\title{
Unconscious incompetence
}

\section{John Launer}

The former US secretary of defence Donald Rumsfeld has been widely and famously lampooned for a statement he made at a press conference in 2002 when threatening to invade Iraq. Here is what he said: 'There are known knowns. These are things we know that we know. There are known unknowns. That is to say, there are things that we now know we don't know. But there are also unknown unknowns. These are things we do not know we don't know.' ${ }^{1}$ Mr Rumsfeld's language was inelegant, and his logic was perverse: he was arguing that you could attack another country just in case they were up to something you didn't know about. Yet, as many people have pointed out, the principle that Rumsfeld stated was itself a legitimate one. It has been proposed in a variety of different contexts including cognitive psychology, philosophy and even religion. It is also a matter of common sense. We make our decisions on the basis of limited knowledge and best guesses, but we can be proved wrong at any moment by factors we never realised were relevant in the first place.

One of the most familiar versions of the Rumsfeld principle occurs in learning theory and is sometimes used when teaching people to become clinical supervisors. ${ }^{2}$ According to this version, we go through four stages of learning in any subject. To begin with, there are a vast number of 'unknown unknowns', and we are in a state of 'unconscious incompetence'. Next, we start to get a sense of our own ignorance and limitations and enter the phase of socalled 'conscious incompetence'. Once we realise and accept this, we can then begin the slow acquisition of understanding and start to gain some elements of 'conscious competence'. In time, our mastery of facts and decision-making in certain areas will become so automatic that we then work mainly through intuition and past experience, a state of mind described as 'unconscious competence'.

\section{RECURRING PATTERN}

The competence cycle isn't something you complete just once. It's an ever-recurring

Correspondence to Dr John Launer, London Deanery, Stewart House, London WC1B 5DN, UK; jlauner@ londondeanery.ac.uk pattern that happens throughout your career, as you extend your appreciation of what you didn't already know, gain the courage to recognise this, and then find the motivation to move forward. It applies to major learning tasks, such as becoming a doctor, learning a language or mastering a musical instrument. It also applies to small, everyday activities where we get something wrong, recognise why, and then correct it. To take a common example, I sometimes can't find a small object. When someone reminds me to put on my glasses, I find the lost object within seconds, virtually without thinking. I have in effect moved rapidly through the cycle from unconscious incompetence to unconscious competence. Interestingly, I may feel annoyed with the person who noticed me struggling and reminded me of one of my limitations-an important point when it comes to understanding how we sometimes resist learning from others.

This example can serve as a helpful metaphor for a great deal of medical activity. As doctors, we generally have the power to choose which perceptual lenses we use at work. In consultations, we ask the questions we consider to be most relevant, but remain unaware of the information that might have been be brought forth if we had asked the patient a different set of questions. We offer people advice and make decisions on the basis of things we believe are certain, without necessarily stopping to check if our certainty is properly grounded. If we realise there are things we don't know, we check these with others or look them up in books or on the web. However, we still miss out on making kinds of inquiry that have never occurred to us and may be highly relevant. If someone reminds us of our limitations-by telling us that we have forgotten to put on the perceptual glasses that were needed for each situation-we may feel quite resentful at their intervention. We prefer to do everything within the safe domain of 'known knowns' and 'known unknowns' rather than contemplating the worrying area of the 'unknown unknowns'.

\section{ENGAGING IN DIALOGUE}

Unconscious incompetence is inevitable in practising medicine, as in any other field. By definition, we cannot be aware of what we don't know we don't know. However, there are several reasons why we should now tackle this head on as a profession. Medical practice has moved from being a solitary vocation to becoming a far more collective activity: no single practitioner's view of what is right or wrong can be justified any longer on the grounds of professional autonomy. In addition, the amount of information now available to aid decisionmaking is in many cases so vast, and often so contradictory, that no human mind can possibly process it intelligently without engaging in dialogue with another mind. Most important of all, patients are acquiring the skills and knowledge to challenge the tricks that we all use in order to conceal our limitations to them or to ourselves: surmises dressed up as facts, misapplied evidence, baseless reassurance and so on

Resistance to working on 'unknown unknowns' can be overcome, and systematically addressed. Many of the learning methods for challenging unconscious incompetence are simple, easily available, and cost little or nothing to apply. They include random case analysis after clinical sessions, mutual observation of consultations by peers, written feedback from patients on the skills their doctors have demonstrated in consultations, keeping systematic records in each consultation of what we were not absolutely sure about, and regular team meetings for discussing problematical or complex cases. These approaches can be used not only in the context of training but as routine ways of helping practitioners to become aware of their blind spots and learning needs.

My prediction is that such approaches will become taken for granted within the working lives of most doctors currently practising. In spite of Donald Rumsfeld's claim, 'unknown unknowns' are not a pretext for invading other people's lives, with possibly fatal consequences. They are an invitation to self-examination, and a continual exchange of views with others.

Competing interests None.

Provenance and peer review Commissioned; not externally peer reviewed.

Postgrad Med J 2010;86:628.

doi:10.1136/pgmj.2010.108423

\section{REFERENCES}

1. Department of Defense News Briefing - Secretary Rumsfeld and General Myers 2002. http://www. defense.gov/transcripts/transcript.aspx? transcriptid $=2636$.

2. Proctor B. Training for the supervision attitude, skills and intention. In: Cutcliffe J, Butterworth T, Proctor B, eds. Fundamental themes in clinical supervision. London: Routledge, 2001. 